DOI: $10.37190 /$ epe 170201

\author{
ALEKSANDRA KLIMONDA ${ }^{1}$, MARTYNA GRZEGORZEK ${ }^{1}$, \\ KATARZYNA MAJEWSKA-NOWAK ${ }^{1}$
}

\title{
REMOVAL OF FLUORIDE IONS BY ULTRAFILTRATION IN THE PRESENCE OF CATIONIC SURFACTANTS
}

\begin{abstract}
The usability of surfactant-aided ultrafiltration for removal of fluoride ions from aqueous solutions has been investigated. The experiments were conducted with the use of cellulose and polyethersulfone membranes. Fluoride solutions containing 10 and $100 \mathrm{mg} \mathrm{F}^{-} / \mathrm{dm}^{3}$ and cationic surfactants: octadecylamine acetate (ODA) and hexadecylpyridium chloride (CPC) were used in the experiments. The concentration of surfactants amounted to $320-960 \mathrm{mg} / \mathrm{dm}^{3}$. Ultrafiltration process was run under a transmembrane pressure of $0.2 \mathrm{MPa}$. In the course of experiments, the effects of initial fluoride concentration, surfactant concentration and membrane type on the fluoride retention coefficient as well as the permeate flux were studied. It was found that the increase of the surfactant concentration effected in improvement of the separation efficiency. On contrary, the permeate flux decreased upon increase of the surfactant concentration. The process efficiency was also strongly influenced by the membrane and surfactant type. The permissible concentration of fluoride in the final product (below $1.5 \mathrm{mg} \mathrm{F}^{-} / \mathrm{dm}^{3}$ ) was obtained for the test with initial solutions containing $10 \mathrm{mg} \mathrm{F}^{-} / \mathrm{dm}^{3}$, polyethersulfone membrane and CPC concentration equal to 644 and $966 \mathrm{mg} / \mathrm{dm}^{3}$.
\end{abstract}

\section{INTRODUCTION}

The presence of fluorine is common in the environment. The occurrence of fluorine in groundwater is ascribed to geological processes. Natural sources of fluorine compounds in drinking water are minerals like cryolite, fluorite or fluoroapatite. The weathering and leaching processes result in fluorine migration to water. Fluorine compounds can also enter the environment through anthropogenic activity which is associated with urbanisation and industrial development. The main sources of fluorine in surface water are fertilizer and pesticide industry, as well as brick and cement factories [1,2].

${ }^{1}$ Wrocław University of Science and Technology, Faculty of Environmental Engineering, Wybrzeże Wyspiańskiego 27, 50-370 Wrocław, Poland, corresponding author A. Klimonda, e-mail address: aleksandra.klimonda@pwr.edu.pl 
Fluorine is a chemical element of atomic number 9 of the halogen group, a poisonous yellow irritating gas with a strong odour. It is chemically reactive. In water, fluorine exists in the form of fluoride ions. Fluorine may be present in air (as gases or particulates), in water, in rocks, in living organisms or in soils [3].

Fluorine is an essential element for living organisms. As a component of drinking water, fluorine has both beneficial and negative impact on human health, depending upon their concentration [4]. Their deficiency can lead to dental caries and possibly osteoporosis [5]. An excess of fluoride in drinking water may result in fluorosis and bones lesion, Alzheimer disease or liver failure. In organisms, most of fluorine compounds are retained in bones and teeth [6]. No medical treatment is available to reverse the effects of fluorosis [4]. Fluorine is eliminated from the human body primarily through the urine [7]. Adult organisms accumulate approximately $60 \%$ of fluorine ingested, while infants accumulate from 80 to $90 \%$ [8]. The consumption of large doses of fluorine results in a chronic toxicity. Fluorine is a general tissue poison, more toxic than lead and just somewhat less than arsenic [9]. Fluorine consumption in dose exceeding $15 \mathrm{mg} / \mathrm{kg}$ body weight may be lethal [10]. In view of its significant impact on human health, fluorine concentration in drinking water pursuant to WHO guidelines [11] cannot exceed $1.5 \mathrm{mg} \mathrm{F}^{-} / \mathrm{dm}^{3}$.

Various water treatment methods have been employed to remove fluoride ions such as precipitation, coagulation, ion exchange, and adsorption or reverse osmosis [12-14]. However, these methods may not be cost-effective.

Surfactant-aided membrane processes are alternative techniques enabling removal of organic and inorganic low-molecular-weight contaminants from aqueous solutions. Micellar-enhanced ultrafiltration (MEUF) is a hybrid process of classic ultrafiltration with the ability of surface active agents to solubilise organic and mineral compounds in the micelles or to bound ionic impurities having the opposite charge to the charge of surfactant at surface of the micelles.

A literature survey shows that organic pollutants like dyes [15] can be removed in MEUF. This process is also effective in removal of almost all heavy metal ions [16, 17]. Considerations of separation of anionic contamination by MEUF refer to phosphates and nitrates [18].

MEUF is based on the surfactant addition into water solution in excess in relation to the critical micelle concentration (CMC). At concentrations higher than $\mathrm{CMC}$, micelles are spontaneously formed from surfactant monomers. Micelle diameters are larger than the UF membrane pores. As a result, solubilised or bounded impurities are rejected by the membrane and concentrated in the retentate while the permeate stream is nearly free of contaminants. This separation process combines high rejection coefficients of reverse osmosis with large permeate fluxes and low transmembrane pressure of ultrafiltration [19].

Type of pollutant determines surfactants used in the MEUF. For removal of anionic pollutants, cationic surfactants are being used. Electrostatic interaction between positive 
surface charge of created micelles and negative charge of anionic impurities results in binding contaminants at micelle surface.

De and Mondal [20] studied the MEUF process for fluoride removal from solution containing $15 \mathrm{mg} \mathrm{F}^{-} / \mathrm{dm}^{3}$ with the use of hexadecylpyridium chloride (CPC). Surfactant concentration amounted to 30,35, 40, 45 and $50 \mathrm{CMC}$. Authors reported fluoride removal from $78 \%$ with CPC concentration equal to $30 \mathrm{CMC}$ to $94 \%$ with $50 \mathrm{CMC}$. These results confirm the suitability of MEUF in fluoride ion removal, although such high concentrations of surfactant in economic scale seem to be unrealistic.

The aim of the experimental research was to evaluate the removal efficiency of fluoride ions from water solutions by surfactant-enhanced ultrafiltration using polyethersulfone (PES) and cellulose (C) membranes and cationic surfactants: octadecylamine acetate (ODA) and hexadecylpyridium chloride (CPC).

\section{EXPERIMENTAL}

Membranes and experimental installation. Intersep Nadir asymmetric ultrafiltration membranes made of polyethersulfone (PES 4) and cellulose (CEL 5) were used. The membranes were characterized by various hydrophilicity and cut-off values and (Table 1). The molecular weight cut-off (MWCO) of the polyethersulfone and cellulose membranes was 4 and $5 \mathrm{kDa}$, respectively.

Table 1

Characteristics of the applied membranes

\begin{tabular}{|c|l|c|l|c|}
\hline $\begin{array}{c}\text { Membrane } \\
\text { type }\end{array}$ & \multicolumn{1}{|c|}{$\begin{array}{c}\text { Membrane } \\
\text { polymer }\end{array}$} & $\begin{array}{c}\text { MWCO } \\
{[\mathrm{kDa}]}\end{array}$ & \multicolumn{1}{|c|}{ Hydrophilicity } & $\begin{array}{c}\text { Distilled water flux }\left(J_{0}\right) \\
\text { under } 0.2 \mathrm{MPa} \\
{\left[\mathrm{m}^{3} /\left(\mathrm{m}^{2} \cdot \text { day }\right)\right]}\end{array}$ \\
\hline PES 4 & polyethersulfone & 4 & moderately hydrophilic & 0.43 \\
\hline CEL 5 & cellulose & 5 & definitely hydrophilic & 0.92 \\
\hline
\end{tabular}

MEUF was conducted using a laboratory-scale ultrafiltration system with an Amicon 8400 UF cell. The effective surface area of the membrane was $45.4 \mathrm{~cm}^{2}$. The total volume of the UF cell amounted to $350 \mathrm{~cm}^{3}$. The process was performed under a transmembrane pressure of 0.2 MPa. Before the first cycle, the UF membranes were treated with distilled water at $0.2 \mathrm{MPa}$ until a constant volume flux was stabilized (Table 1).

Reagents. Aqueous solutions were prepared with distilled water and the sodium fluoride $(\mathrm{NaF})$. The concentrations of fluoride ions in the model solutions were equal to 10 and $100 \mathrm{mg} \mathrm{F}^{-} / \mathrm{dm}^{3}$. In the tests, cationic surfactants such as octadecylamine acetate (ODA) and hexadecylpyridium chloride (CPC) were used. The surfactant concentration ranged from 320 to $960 \mathrm{mg} / \mathrm{dm}^{3}$ (which corresponds to 1-3 CMC) (Table 2). 
Table 2

Concentrations of surfactants used in MEUF $\left[\mathrm{mg} / \mathrm{dm}^{3}\right]$

\begin{tabular}{|l|c|c|c|}
\hline \multicolumn{1}{|c|}{ Surfactant } & 1 CMC & 2 CMC & 3 CMC \\
\hline Octadecylamine acetate ODA & 296.9 & 593.2 & 889.8 \\
\hline Hexadecylpyridium chloride CPC & 322.2 & 644.4 & 966.6 \\
\hline
\end{tabular}

Methods. During the experiments, permeate volume fluxes were appointed. Permeate flux $(J)$ was calculated from:

$$
J=\frac{V}{t a} \quad\left[\mathrm{~m}^{3} /\left(\mathrm{m}^{2} \cdot \text { day }\right)\right]
$$

where $J$ is the permeate volume flux $\left(\mathrm{m}^{3} /\left(\mathrm{m}^{2} \cdot\right.\right.$ day $\left.)\right), V$ denotes the volume of a permeate sample collected within time $t$ (day) and $A$ is the effective membrane surface area $\left(\mathrm{m}^{2}\right)$.

To determine the membrane susceptibility to fouling, the relative permeability $J / J_{0}$, was evaluated ( $J_{0}$ - distilled water flux). The efficiency of MEUF in fluoride removal was calculated by retention coefficient:

$$
R=\frac{C_{0}-C}{C_{0}} \times 100 \%
$$

where $R$ is the fluoride retention coefficient (\%), $C_{0}$ denotes the initial concentration of fluoride ions and $C$ denotes their concentration in permeate (in $\mathrm{mg} / \mathrm{dm}^{3}$ ).

Fluoride concentration in aqueous solutions was measured by the spectrophometric method. A spectrofotometer DR $2000(\mathrm{HACH})$ was used for fluoride ion analysis. Colorimetric analysis with SPADNS reagent was performed. This method is based on the reaction of fluoride with red zirconium dye solution. Fluoride ions form a colourless complex with zirconium, thus reducing the intensity of the red colour in proportion to the fluoride concentration.

\section{RESULTS AND DISCUSSION}

\subsection{TRANSPORT PROPERTIES}

As an important parameter of membrane separation processes, permeability of membranes was measured for all tests. According to literature reports [21], the hydrophilic membrane CEL 5 was characterized by a higher volume flux than the moderately hydrophilic membrane PES 4 . In the tests with distilled water, volume flux for the 
CEL 5 membrane amounted to $0.92 \mathrm{~m}^{3} /\left(\mathrm{m}^{2}\right.$.day), whereas for the membrane PES 4 it was equal to $0.43 \mathrm{~m}^{3} /\left(\mathrm{m}^{2}\right.$.day) (under $0.2 \mathrm{MPa}$ ). The experiments with the surfactant solutions confirmed better permeability of the cellulose membrane than that of the polyethersulfone membrane.
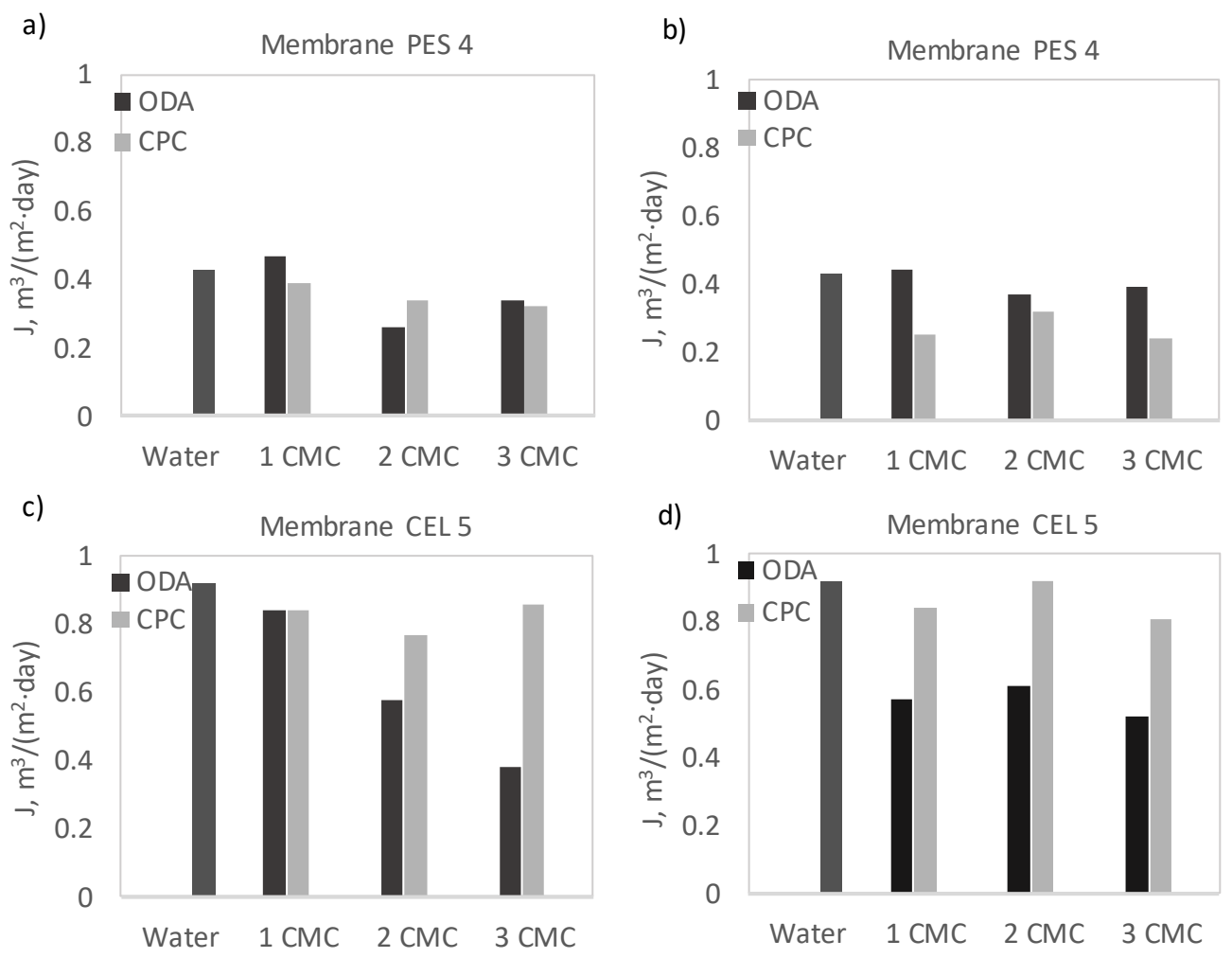

Fig. 1. Volume flux $(J)$ for membranes made of polyethersulfone (PES 4) and cellulose (CEL 5) versus CPC and ODA concentration: a), b) $C_{0}=10 \mathrm{mg} \mathrm{F}^{-} / \mathrm{dm}^{3}$, c), d) $C_{0}=100 \mathrm{mg} \mathrm{F}^{-} / \mathrm{dm}^{3}$ )

The presence of surfactants in tested solutions as well as initial concentration of $\mathrm{F}^{-}$ions strongly influence the membrane permeability (Fig. 1). Literature data report [22] that hydrophilic membranes are more fouling resistant than membranes made of hydrophobic materials. Application of CPC in the ultrafiltration system with a definitely hydrophilic membrane CEL 5 resulted in a small aggravation of transport properties (Figs. $1 \mathrm{~b}$ and $2 \mathrm{~d}$ ), while the presence of ODA in the system significantly reduced the volume flux. For solutions containing $3 \mathrm{CMC}$ of ODA and $10 \mathrm{mg} \mathrm{F} / \mathrm{dm}^{3}$, a twofold drop decrease of the permeability (in comparison to water flux), i.e. from 0.92 to 0.38 was observed. Contrary to literature reports [22], results of the experiments with the use of CEL 5 and ODA testified membrane susceptibility to fouling. 
Thus, the presence of the surface active agent ODA in solution caused volume flux reduction (Figs. 1b, d).

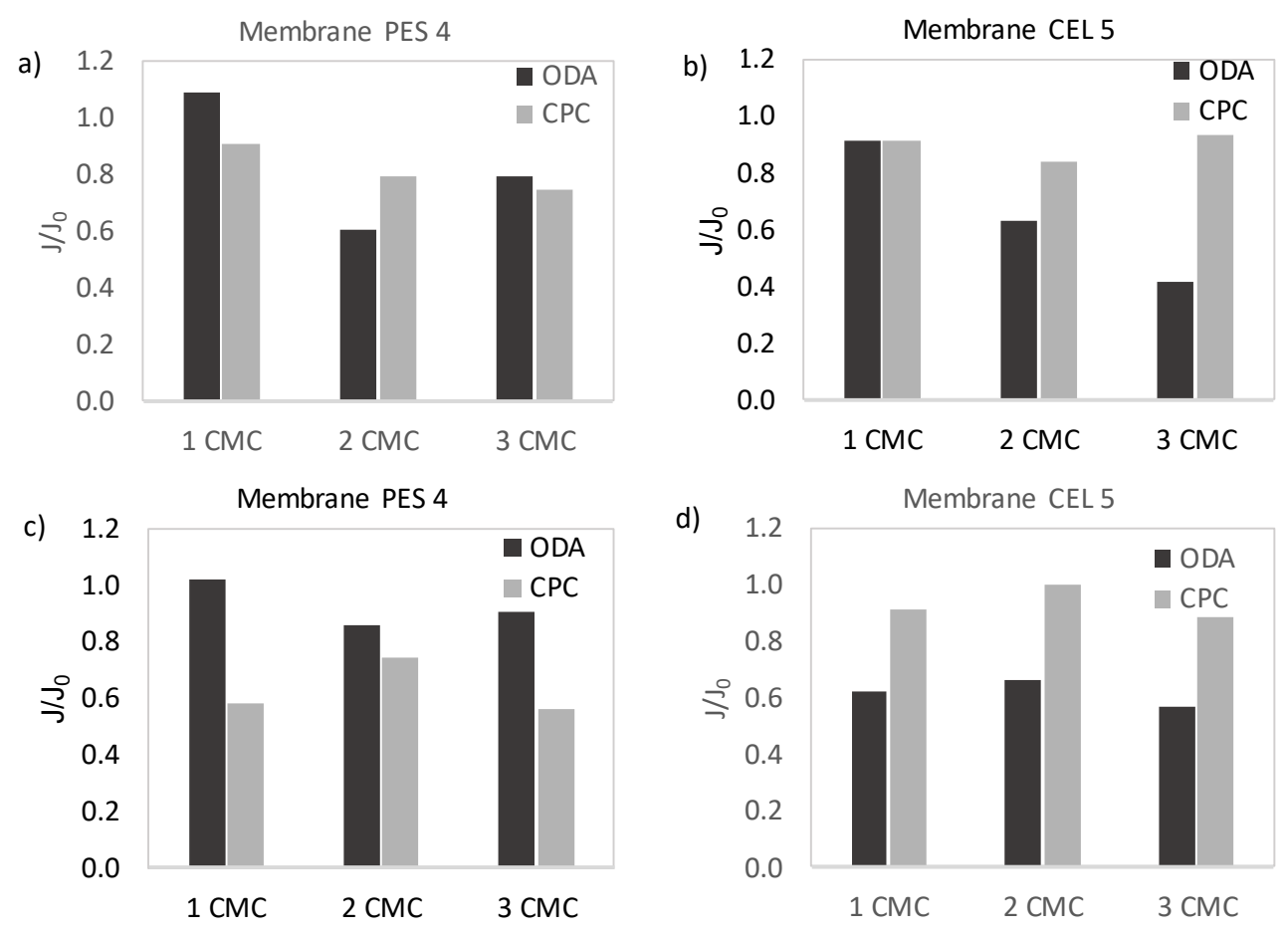

Fig. 2. Membrane relative permeability $\left(J / J_{0}\right)$ for membranes made of polyethersulfone (PES 4) and cellulose (CEL 5) vs. CPC and ODA concentration:

a), b) $C_{0}=10 \mathrm{mg} \mathrm{F}^{-} / \mathrm{dm}^{3}$, c), d) $C_{0}=100 \mathrm{mg} \mathrm{F}^{-} / \mathrm{dm}^{3}$ )

The results presented in Figs. 1 and 2 show general correlation between increasing surfactant concentration and membrane susceptibility to fouling. In most of tests, increasing dosage of surfactants resulted in worsening of transport properties, although in two experiments a phenomenon of improving membrane permeability was observed. Application of PES 4 membrane with ODA resulted in a relative permeability $\left(J / J_{\mathrm{o}}\right)$ higher than 1 (Figs. 2a, c). This phenomenon may be explained by the surfactant's impact on membrane surface. Moderately hydrophilic polyethersulfone membrane being in contact with ODA can be converted into more hydrophilic structure.

Due to rather low wettability, the moderately hydrophilic PES 4 membrane was prone to fouling caused by sorption of surfactant molecules. Surfactant monomers can be adsorbed at the membrane surface and inside membrane pores which leads to pore size decrease. As a result, the permeability deterioration was observed. On the other hand, this phenomenon might contribute to improvement of $\mathrm{F}^{-}$ions rejection. 


\subsection{SEPARATION PROPERTIES}

The effect of membrane MWCO and surfactant type, as well as solution composition on fluoride removal was investigated. Figure 3 shows the influence of ODA and CPC concentration on fluoride retention with the use of PES 4 and CEL 5 membranes.

Generally, a distinct relationship between surfactant concentration and process efficiency was observed. In all experiments, an increase of surfactant dose resulted in improvement of separation efficiency (Fig. 3). High surfactant doses (above 1 CMC) resulted in increasing the size of the micelles as well as the number of aggregates. Thus, more fluoride ions may be bound to the micelle surface.
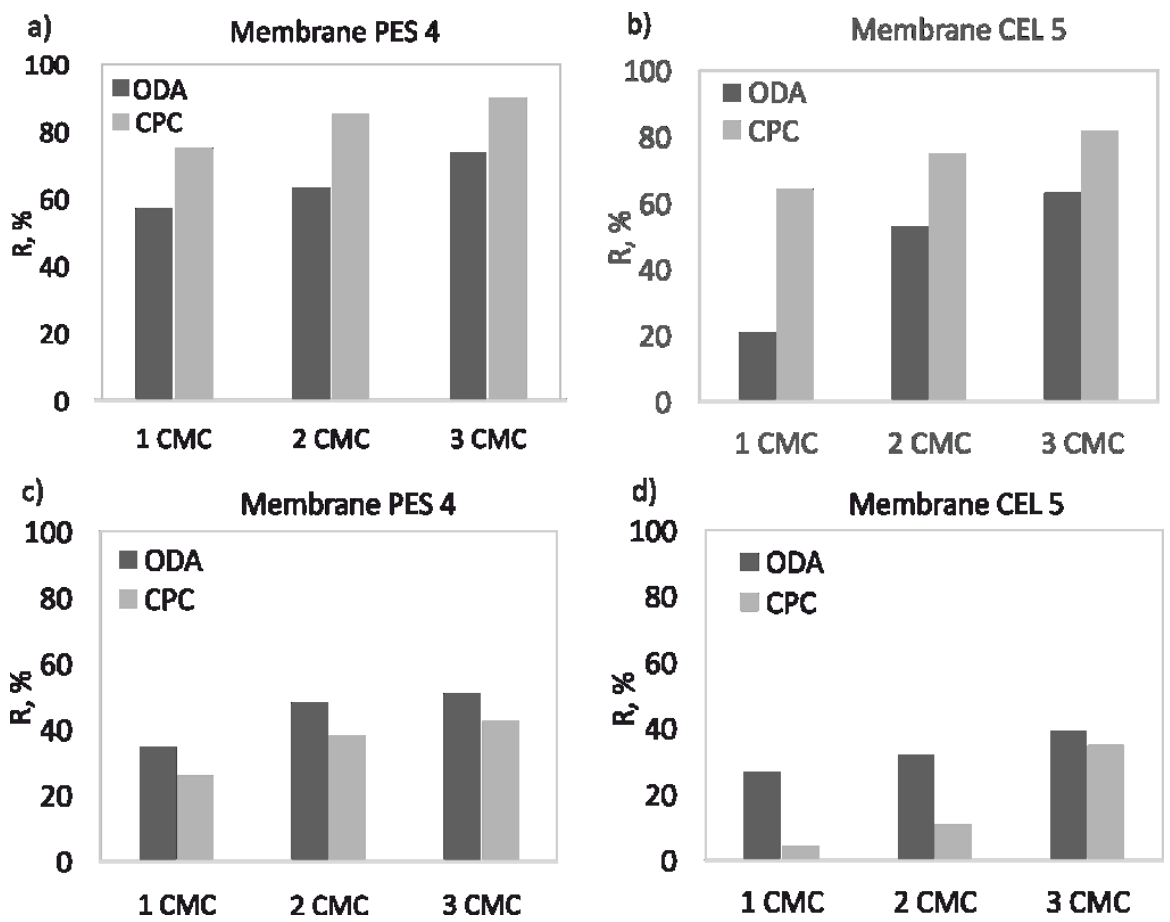

Fig. 3. Fluoride ion retention coefficient $(\mathrm{R})$ for membranes made of polyethersulfone (PES 4) and cellulose (CEL 5) vs. CPC and ODA concentration in model aqueous solutions: a), b) $C_{0}=10 \mathrm{mg} \mathrm{F}^{-} / \mathrm{dm}^{3}$, c), d) $C_{0}=100 \mathrm{mg} \mathrm{F}^{-} / \mathrm{dm}^{3}$ ).

The experiments confirmed the effect of membrane properties on the $\mathrm{F}^{-}$ions retention coefficient. For tests with the initial concentration of $10 \mathrm{mg} \mathrm{F}^{-} / \mathrm{dm}^{3}$ (Fig. 3a) and moderately hydrophilic membrane PES 4, the retention coefficient varied from 75 to $90 \%$ with CPC surfactant and from 57 to $74 \%$ with ODA surfactant. Similar correlation was observed when solutions containing $100 \mathrm{mg} \mathrm{F}^{-} / \mathrm{dm}^{3}$ (Fig. 3c) were used. Moderately hydrophilic membrane (PES 4) retained from 26 to $38 \%$ of $^{-}$ions with CPC surfactant 
and $35-51 \%$ when ODA was used. Due to lower MWCO, better separation properties for the PES 4 membrane than for the CEL 5 membrane were observed.

The use of more hydrophilic membrane CEL 5 (Fig. 3b) resulted in inferior retention coefficients in a range from 21 to $63 \%$ with application of CPC and from 64 to $82 \%$ with the use of ODA when $\mathrm{F}^{-}$concentration in solution was equal to $10 \mathrm{mg} \mathrm{F}^{-} / \mathrm{dm}^{3}$. Experiments with solution containing $100 \mathrm{mg} \mathrm{F}^{-} / \mathrm{dm}^{3}$ in the presence of ODA and CPC resulted in retention coefficient of $27-39 \%$ and $4-35 \%$, respectively.

Analysis of the results obtained proved the suitability of MEUF to fluoride removal from model solutions of a low $\mathrm{F}^{-}$ions concentration $\left(10 \mathrm{mg} \mathrm{F}^{-} / \mathrm{dm}^{3}\right)$. The experiments with PES 4 membrane and CPC surfactant (2 and $3 \mathrm{CMC}$ ) enabled fluoride rejection from 85 to $90 \%$ (Fig. 3a). This retention range leads to fluoride concentration in permeate at a level of $1.0-1.5 \mathrm{mg} \mathrm{F}^{-} / \mathrm{dm}^{3}$. Thus, it can be stated that MEUF permeate meets the drinking water standard towards fluoride content (in pursuance of WHO guidelines).

\section{CONCLUSIONS}

- Surfactant-aided ultrafiltration is a suitable technique for removal of fluoride ions from solutions containing low amounts of $\mathrm{F}^{-}$. Application of PES 4 membrane and CPC surfactant (at initial fluoride concentration of $10 \mathrm{mg} \mathrm{F}^{-} / \mathrm{dm}^{3}$ ) results in permeate quality fulfilling the WHO guidelines for drinking water $\left(\mathrm{F}^{-}\right.$concentration lower than $\left.1.5 \mathrm{mg} \mathrm{F}^{-} / \mathrm{dm}^{3}\right)$.

- Increasing concentration of surfactant brings about improvement of fluoride retention and worsening of membrane permeability.

- A slight modification of membrane hydrophilicity under the contact with surface active agent can be observed.

- In the course of surfactant-aided ultrafiltration membrane fouling can be observed. This phenomenon is especially pronounced for moderately hydrophilic PES membrane under the contact with ODA surfactant. Definitely hydrophilic CEL membrane enables better fouling resistant but poorer fluoride rejection (in comparison to PES membrane).

\section{ACKNOWLEDGMENTS}

The work was funded by a grant No. 0402/0080/16 from the Department of Environmental Engineering, Wrocław University of Science and Technology.

\section{REFERENCES}

[1] Matsuzawa K., Atarashi D., Miyauchi M., Sakai E., Interactions between fluoride ions and cement paste containing superplasticizer, Cem. Concr. Res., 2017, 91, 33.

[2] WANG H., Li R., FAN C., FENG J., JiAnG S., HAN S., Removal of fluoride from the acid digestion liquor in production process of nitrophosphate fertilizer, J. Fluorine Chem., 2015, 180, 122.

[3] Weinstein L.H., Davison A., Fluorides in the Environment, CABI Publishing, 2004. 
[4] Jadhav S.V., Bringas E., Yadav G.D., Rathod V.K., Ortiz I., Marathe K.V., Arsenic and fluoride contaminated groundwaters. A review of current technologies for contaminants removal, J. Environ. Manage., 2015, 162, 306.

[5] Ozsvath D.L., Fluoride and environmental health. A review, Rev. Environ. Sci. Bio., 2009, 8 (1), 59.

[6] O'mullane D.M., Baez R.J., Jones S., Lennon M.A., Petersen P.E., RugG-Gunn A.J., Whelton H., Whitford G.M., Fluoride and oral health, Comm. Dent. Health, 2016, 33, 69.

[7] BŁaszczyk I., RatajczaK-Kubiak E., Birkner E., Advantageous and harmfully effect of fluoride, Farm. Pol., 2009, 65 (9), 623 (in Polish).

[8] Fawell J., Bailey K., Chilton J., Dahi E., Fewtrell L., Magara Y., Fluoride in Drinking-Water, World Health Organization (WHO), 2006.

[9] Ranjan R., Ranjan A., Fluoride Toxicity in Animals, Springer Briefs in Animal Sciences, 2015.

[10] Pujara N., Pujara P., Fluoride Toxicity. A Systematic Review, Int. J. Sci. Res., 2015, 4 (6), 2784.

[11] WHO, Guidelines for Drinking Water Quality, World Health Organization, 2006.

[12] Waghmare S.S., ARFin T., Fluoride removal from water by various techniques. Review, Int. J. Inn. Res. Sci., Eng. Techn., 2015, 2 (9) 560.

[13] Samadi M.T., Zarrabi M., StePhr M.N., Ramhormozi S.M., Azizian S., Amrane A., Removal of fluoride ions by ion exchange resin. Kinetic and equilibrium studies, Environ. Eng. Manage. J., 2014, 13 (1), 205.

[14] SEHN P., Fluoride removal with extra low energy reverse osmosis membrane. Three years of large scale field experience in Finland, Desalination, 2008, 223, 73.

[15] MaJewsKa-NowaK K., Separation of organic dyes from aqueous solutions by ultrafiltration in the presence of an anionic surfactant, Ochr. Śr., 2006, 28 (3), 15 (in Polish).

[16] LeE S.H., SHRESTHA S., Application of micellar enhanced ultrafiltration (MEUF) process for zinc(II) removal in synthetic wastewater. Kinetics and two-parameter isotherm models, Int. Biodeterior. Biodegr., 2014, 95, 241.

[17] YenPHAN P., CHANCHAI A., JiRARATANANON R., Experimental study on micellar-enhanced ultrafiltration (MEUF) of aqueous solution and wastewater containing lead ion with mixed surfactants, Desalination, 2010, 253, 30.

[18] GóRna J., MAJEWSKA-NowAK K., Removal of inorganic nitrogen and phosphorous compounds from two-component aqueous solutions by micellar enhanced ultrafiltration, Environ. Prot. Eng., 2015, 41 (2), 167.

[19] GÓRNA J., MAJEWSKA-NOWAK K., Removal of nitrates from aqueous solutions by micellar-enhanced ultrafiltration with the use of ceramic membranes, Membr. Membr. Proc. Environ. Prot., 2014, 119, 9.

[20] De S., Mondal S., Micellar Enhanced Ultrafiltration Fundamentals \& Applications, Taylor and Francis, Boca Raton 2012.

[21] Kabsch-Korbutowicz M., Majewska-NowaK K., Analyzing the phenomenon of membrane fouling in the course of water treatment by ultrafiltration, Ochr. Śr., 1998, 71 (4), 11 (in Polish).

[22] BAKer R.W., Membrane Technology and Applications, Wiley, Menlo Park 2004. 